\title{
Prevalence and correlates of being bullied among adolescents in Indonesia: results from the 2015 Global School-based Student Health Survey
}

\author{
${ }^{1}$ Faculty of Nursing, Universitas Airlangga, Surabaya, Indonesia, E-mail: ferry-e@fkp.unair.ac.id. \\ https://orcid.org/0000-0002-6669-0767, https://orcid.org/0000-0002-6836-034X. \\ ${ }^{2}$ Center for Planning and Management of Human Resources for Health, Ministry of Health, Jakarta, Indonesia
}

\begin{abstract}
:
Introduction: Violence against adolescents is prevalent in the world, yet this issue is neglected especially in developing countries. Bullying among adolescents negatively affects the victims in relation to emotional, physical, social and overall health status. This study was conducted to understand bullying and its associated factors in school-going adolescents in Indonesia.

Methods: This study was a correlational design with a cross-sectional approach. Data were obtained from the 2015 Indonesia Global School-based Health Survey (GSHS). As many as 9969 adolescents in schools were selected by probability proportional to size method and systematic sampling. Variables analyzed on this study were age, sex, smoking behavior, alcohol consumption, close friends and feeling of loneliness. The research instrument used the GSHS 2015 questionnaire. Chi-square $\left(\chi^{2}\right)$ analysis and multiple logistic regression tests were conducted to determine the significance of each variable.

Results: A total of $19.9 \%$ of adolescents in Indonesian schools were victims of being bullied. Being bullied was associated with $\leq 14$ years old [adjusted odds ratio (AOR) 1.30, 95\% confidence interval (CI) 1.17-1.45], being male (AOR 1.43, 95\% CI 1.28-1.59), being a smoker (AOR 1.46, 95\% CI 1.23-1.73), consuming alcohol (AOR 2.07, $95 \%$ CI 1.64-2.62), having no close friends (AOR 1.27, 95\% CI 0.95-1.70) and feeling lonely (AOR 2.29, 95\% CI 2.05-2.55).

Conclusion: Indonesian in-school adolescents report a relatively high prevalence of having been bullied. Being bullied is related to various factors depending on personal and environmental factors. School communities and health professionals' attention to adolescents should be sensitized and this issue discussed, developing strategies and minimizing the negative effect on the adolescents. Policy makers need to consider developing a social platform among adolescents to facilitate students' interaction.
\end{abstract}

Keywords: adolescent, bullying, Global School-based Student Health Survey, loneliness

DOI: $10.1515 /$ ijamh-2019-0064

Received: March 19, 2019; Accepted: April 16, 2019

\section{Background}

One of the most common forms of physical and emotional violence on children and adolescents is bullying [1], [2]. Bullying among adolescents is a global concern and is widely known to negatively affect the victims [3], [4]. Bullying refers to aggressive behaviors with intentions to harm or abuse another person in repetitive actions and involves a power imbalance [5]. Bullying that happens in a school setting requires greater attention as a school is a place for adolescents to undertake a formal learning process and, therefore, it affects the quality of life for future generations [6].

Indonesia is one of the countries that is exposed to a high number of aggressive acts, such as bullying behavior among adolescents, although there is a lack of comprehensive data [7]. As many as $40 \%$ of adolescents have been bullied in school and $32 \%$ have reported that they have been victims of physical violence [8]. The survey results of the Social Affairs Ministry of Indonesia in 2013 showed that one out of two male adolescents $(47.45 \%)$ and one out of three female adolescents $(35.05 \%)$ had been bullied [9]. Further data from the Global School-based Student Health Survey (GSHS) 2015 showed that $24.1 \%$ of male adolescents and $17.4 \%$ female adolescents have been bullied [10]. In addition, the Ministry of Women Empowerment and Child Protection of Indonesia has warned the nation about the serious impact of bullying, especially in a school setting [11]. 
A considerable amount of literature has been published on the magnitude of the effect of bullying on an adolescent's life, especially at school. These studies conclude that higher levels of bullying at school decrease academic performance [6] and lead to depression, higher levels of anxiety, lower levels of self-esteem [12], a high level of aggression [13], and violence-related behaviors [14]. Furthermore, existing literature has linked psychosocial problems with poor health outcomes, especially in school settings [15]. It also leads to behavior such as absence from school to avoid the bullying perpetrators [16], staying away from school-related activities [17] and certain places at school [16]. Violence among adolescents at school requires global attention, especially in terms of the policy structure of each nation to promote anti-bullying programs in schools [18].

Several researches have highlighted the following factors that are associated with bullying: demographic factors, social factors, lifestyle factors and living and working conditions [4], [19], [20], [21], [22]. Factors related to bullying include gender, as males are especially susceptible to bullying, younger ages, physical contact, mental stress, drug use, risky health behaviors such as sexual behavior, poor hygiene and physical activities [4], [19], [21]. In addition, there are also other factors, such as having close friends, strict parental supervision and skipping school [23]. Likewise, research carried out in countries with low and middle incomes found that cases of bullying were associated with demographic factors, health risk behaviors and physical activity [19].

Some previous research in Indonesia reported that the most widely experienced form of bullying by adolescents is verbal bullying [24]. Despite the growing prevalence of adolescents being bullied in Indonesia, little is known, however, as to what factors affect individuals becoming the victims of bullying using nationwide data. Understanding the individual factors may help to recognize the real situation faced by bullied adolescents. For this purpose, this study is aimed to investigate factors associated with victims of bullying among adolescents in Indonesia based on the secondary data from the 2015 GSHS.

\section{Methods}

\section{Study design, setting and sample}

The 2015 Indonesian GSHS is a cross-sectional survey administered in schools that collected nationally representative data. This survey was conducted among junior and senior high schools. A two-stage cluster sample design was utilized to generate data representative of all students aged approximately between 11 and 18 years old in Indonesia. Probability proportional to size was used to involve a selection of schools. Systematic sampling was applied to randomly select classes in the selected schools. In the first stage, all schools containing any of class 7-12 were selected. The second stage of sampling involved a process of the random selection of intact classrooms from each selected school. The study participants were selected from 75 schools located at 68 districts/cities from 26 out of 34 provinces in Indonesia. All students from the determined classes were eligible to join in the study.

A questionnaire was used to collect data from all respondents. Details of the questionnaire can be found here: https: / / goo.gl/grG2Ps [25]. The response rate was $94 \%$ of 11,917 sampled students. After excluding missing cases, a total of 9969 respondents was obtained for further analysis.

\section{Data analysis}

Data were analyzed using descriptive statistics to measure the prevalence of dependent variables (have been bullied) and independent variables on a dichotomous scale (age, sex, smoking behavior, alcohol consumption, a close friend and feeling lonely). The selection of variables were based on the previous empirical studies relevant to bullying. To ensure the study participants shared the same understanding on the definition of terms used in the questionnaire, explanations on each item of questions were given to all participants in advance. The participants were also given a chance to ask for further clarity.

The outcome variable was obtained by asking the participants how many days they were bullied within the last 30 days. Participants were categorized as having been bullied (yes) if they experienced bullying on at least 1 day in the past 30 days. Bullying in this study includes various forms of verbal, social and physical bullying. It includes a bad and unpleasant act by a student or a group of students to another powerless student, such as insulting, teasing too much in a nasty way, hitting or leaving someone out on purpose.

For the independent variables, age was dichotomized as those who are 14 years old or younger and 15 years old or older. Sex was dichotomized as male and female. Variables of smoking behavior, alcohol consumption, a close friend and feeling lonely were dichotomized as yes and no. Students were categorized as having smoking behavior or drinking of alcohol (yes) if they had ever tried smoking or drinking of alcohol at least once in the 
past 30 days. Students were categorized as having a close friend (yes) if they mentioned having at least one close friend. Students were classified as feeling lonely (yes) if they said sometimes, most of the time or always felt lonely.

$\chi^{2}$ and logistic regression analysis were conducted to determine the association between independent variables and the outcome variable of being bullied. From the bivariate analysis, factors with a significant association $(\mathrm{p}<0.05)$ to the dependent variable of being bullied were included in the multivariate logistic regression model. Analysis was calculated using IBM SPSS Statistics 25 software (IBM Corp, Armonk, NY, USA). The Hosmer and Lemeshow was performed to test the goodness of fit of the data. The result of the test was $p>0.05$ indicating the model fit to the data. The results of multivariate analysis were presented in adjusted odds ratios (AOR) with a 95\% confidence interval (CI).

\section{Ethical considerations}

The GSHS (2015) was carried out collaboratively under supervision of the Institute of Health Research and Development (Balitbangkes), as part of the Indonesian Ministry of Health (MoH). The review of the research was done by Balitbangkes based on GSHS 2015's ethics protocols. All personal identifications were removed and respondents submitted their written informed consent before the interview started. All data were kept by the $\mathrm{MoH}$ in secure places. The Institutional Review Board of Balitbangkes approved the research protocol with the number LB 02.01/5.2/KE.158/2018.

\section{Result}

\section{Description of the study sample}

Of 9969 participants, about 19.9\% $(\mathrm{n}=1982)$ reported that they had been bullied in the past month. Among those victims of bullying, most of them were aged 14 years old or younger $(65.5 \%)$ and more than half $(51.8 \%)$ were male. Other characteristics of the study sample are presented in Table 1 . All of the variables in the bivariate analysis were significantly associated with being bullied.

Table 1: Individual characteristics of study participants in the Indonesian 2015 GSHS ( $n=9969)$.

\begin{tabular}{|c|c|c|c|c|c|}
\hline & \multicolumn{4}{|c|}{ Victims of bullying } & \multirow[t]{3}{*}{$\chi^{2}$} \\
\hline & \multicolumn{2}{|r|}{ No } & \multicolumn{2}{|r|}{ Yes } & \\
\hline & $\mathbf{n}$ & $\overline{\%}$ & $\mathbf{n}$ & $\overline{\%}$ & \\
\hline \multicolumn{6}{|l|}{ Age } \\
\hline$\geq 15$ years old & 2980 & 37.3 & 684 & 34.5 & $5.365^{\mathrm{a}}$ \\
\hline$\leq 14$ years old & 5007 & 62.7 & 1298 & 65.5 & \\
\hline \multicolumn{6}{|l|}{ Sex } \\
\hline Female & 4598 & 57.6 & 955 & 48.2 & $56.681^{c}$ \\
\hline Male & 3389 & 42.4 & 1027 & 51.8 & \\
\hline \multicolumn{6}{|l|}{ Smoking } \\
\hline No & 7329 & 91.8 & 1683 & 84.9 & $85.794^{\mathrm{C}}$ \\
\hline Yes & 658 & 8.2 & 299 & 15.1 & \\
\hline \multicolumn{6}{|c|}{ Alcohol consumption } \\
\hline No & 7768 & 97.3 & 1832 & 92.4 & $103.763^{\circ}$ \\
\hline Yes & 219 & 2.7 & 150 & 7.6 & \\
\hline \multicolumn{6}{|l|}{ Close friend } \\
\hline No & 188 & 2.4 & 67 & 3.4 & $6.714^{\mathrm{a}}$ \\
\hline Yes & 7799 & 97.6 & 1915 & 96.6 & \\
\hline \multicolumn{6}{|l|}{ Feeling lonely } \\
\hline No & 3685 & 46.1 & 566 & 28.6 & $200.662^{c}$ \\
\hline Yes & 4302 & 53.9 & 1416 & 71.4 & \\
\hline Total & 7987 & 80.1 & 1982 & 19.9 & \\
\hline
\end{tabular}

${ }^{\mathrm{a}} \mathrm{p}<0.05,{ }^{\mathrm{b}} \mathrm{p}<0.01,{ }^{\mathrm{c}} \mathrm{p}<0.001$ 


\section{Factors associated with being bullied}

As shown in Table 2, being a teenager of 14 years old or younger increased the odds of being bullied by $30 \%$ more than older adolescents (AOR 1.30, 95\% CI 1.17-1.45). Adolescents who were male were more likely to be bullied than those who were female (AOR 1.43, 95\% CI 1.28-1.59). Smoking cigarettes also increased the odds of adolescents to be bullied by $46 \%$ more than non-smoking adolescents (AOR 1.46, 95\% CI 1.23-1.73). Adolescents who consumed alcohol were twice more likely to experience bullying victimization compared to adolescents who did not drink alcohol (AOR 2.07, 95\% CI 1.64-2.62). Adolescents who experienced feelings of loneliness were more than twice as likely to experience bullying victimization compared to those who were not lonely (AOR 2.29, 95\% CI 2.05-2.55).

Table 2: Factors associated with being bullied among adolescents in Indonesia, 2015 ( $\mathrm{n}=9969)$.

\begin{tabular}{|c|c|c|c|}
\hline \multirow[t]{2}{*}{ Variables } & \multirow[t]{2}{*}{ AOR } & \multicolumn{2}{|c|}{$95 \%$ CI for EXP (B) } \\
\hline & & Lower & Upper \\
\hline \multicolumn{4}{|l|}{ Age } \\
\hline$\leq 14$ years old & $1.30^{c}$ & 1.17 & 1.45 \\
\hline$\geq 15$ years old & 1 & 1 & 1 \\
\hline \multicolumn{4}{|l|}{ Gender } \\
\hline Male & $1.43^{c}$ & 1.28 & 1.59 \\
\hline Female & 1 & 1 & 1 \\
\hline \multicolumn{4}{|l|}{ Smoking } \\
\hline Yes & $1.46^{\mathrm{c}}$ & 1.23 & 1.73 \\
\hline No & 1 & 1 & 1 \\
\hline \multicolumn{4}{|c|}{ Alcohol consumption } \\
\hline Yes & $2.07^{c}$ & 1.64 & 2.62 \\
\hline No & 1 & 1 & 1 \\
\hline \multicolumn{4}{|l|}{ Close friend } \\
\hline Yes & 1 & 1 & 1 \\
\hline No & 1.27 & 0.95 & 1.70 \\
\hline \multicolumn{4}{|l|}{ Feeling lonely } \\
\hline Yes & $2.29^{c}$ & 2.05 & 2.55 \\
\hline No & 1 & 1 & 1 \\
\hline
\end{tabular}

${ }^{\mathrm{a}} \mathrm{p}<0.05,{ }^{\mathrm{b}} \mathrm{p}<0.01,{ }^{\mathrm{c}} \mathrm{p}<0.001$.

AOR, Adjusted Odds ratio.

\section{Discussion}

This study found that the proportion of in-school adolescents having experienced bullying in the past 30 days was $19.9 \%$. Other countries reported higher rates of bullying among adolescents. A study of bullying in Asian countries, such as Thailand, found higher rates of bullying (27.7\%) [19]. Studies from developed countries, such as Australia, also found a high prevalence of bullying victimization ranging from 10 to $35 \%$ [26]. To date, there are two recognized international surveys measuring violence in adolescents, the GSHS and the Health Behavior in School-aged Children (HBSC) survey. A multi-country study using data from these two types of international surveys reported a global prevalence of bullying among adolescents at approximately $30 \%$. In both different groups of male and female adolescents, the prevalence rates of bullying were found to be higher in African countries than in European countries [27]. The lower prevalence rate of bullying found in this current study may be attributable to the different measurement and perception on bullying. The Indonesia GSHS questionnaire explains that bullying does not include an argument or a fight involving two students with an equal power or strength or making fun in a playful way. Some students might not report of being bullied if their perception of unpleasant things was considered as being merely jokes among friends. In addition, the questionnaire has not incorporated cyberbullying and body shaming, which might also underestimate the prevalence rate. This finding informs us that all parties in Indonesia should take responsibility for educating adolescents about all forms of violence.

In this study, the probability of being bullied is higher among younger adolescents than the older ones. This finding is supported by research in the Caribbean and China that also suggested that younger adolescents are more likely to be victims of bullying [22], [28]. Similarly, another study reported that younger Thai adolescents 
have a greater risk of bullying victimization than older adolescents [19]. Multi-country studies, such as one conducted by the World Health Organization (WHO) in 2014, have shown that the prevalence of being bullied decreases with increased age [18]. Younger adolescents might have been bullied by their older peers or superiors due to lack of power. Some cases of seniority bullying at schools in Indonesia were reported to occur during school orientation [29]. This finding reflects the fact that specific interventions for younger adolescents need to be set up and considered at all levels of schooling.

The study found, in the multivariable analysis among adolescents, that males were associated with being victims of bullying. In a similar vein, a study in America and Malawi explained that boys are more likely to be bullied than girls [21], [30]. Another study using the 2016 GSHS in Sri Lanka also found a significantly higher proportion of males versus females who had been bullied for at least 1 day within 30 days prior to the survey [31]. This finding confirmed the gender stereotype that boys are more accepting of aggressive behavior than girls [32]. We are, therefore, challenged to seek a more complete explanation of this issue and suggest a gendersensitive issue program.

This study found that the risk of being bullied is higher among students who drink alcohol and smoke cigarettes than those who do not. Studies among Zambian and Malawian adolescents reported the same result in that a higher likelihood of being bullied was found among adolescents who drank alcohol [33], [34]. Research in America and Saudi Arabia showed that adolescents who smoke are more likely to have been bullied [35], [36]. There is a possibility that adolescents who consume tobacco or alcohol are in situations or engaged in a social environment that more easily positions them as targets of bullying than those who have no substance abuse. Adolescents who drink alcohol and smoke cigarettes might also be more likely to be bullied than their counterparts due to common negative perception on their behavior. In contrast, having experienced bullying may produce psychosocial distress that drives adolescents to misuse substances such as alcohol and cigarettes so as to reduce the anxiety [37]. More research is needed to provide greater understanding related to this finding, especially in the Indonesian context.

Feelings of loneliness were associated with victims of bullying in our study. Studies in Thailand and Cyprus showed the same result in that adolescents who reported experience in loneliness were more likely to report having the experience of being bullied [38], [39]. Those who are insecure and feel lonely and who may have social problems in making friends, could make them more prone to bullying than other adolescents [40], [41], [42]. Having close relationships with peers is increasingly important among children in early adolescence; therefore,the creation of a social network and improved adolescents' social development at school need to be considered.

\section{Limitation of the study}

This study shows some strengths, including a nationwide scale with a large sample size; however, some limitations do exist. Firstly, causal relationship cannot be determined due to the nature of a cross-sectional study design. Secondly, the data were generated from self-administered questionnaires, which might have potential bias. Next, this study only included adolescents in school and excluded adolescents who were absent on the day of data collection as well as those out-of-school adolescents. Finally, similar to other observational studies, how other unmeasured potential confounding variables might influence these results is uncertain.

\section{Conclusion}

A high prevalence of bullying victims (19.9\%) was reported among Indonesian adolescents in school. Factors of age, sex, alcohol, smoking and loneliness showed positive association with being bullied. This study provided initial data to inform policy makers about prevalence and factors correlated to bullying. Increasing public awareness about bullying and preventive actions among students, other adolescents, parents or families, as well as the community in general, should be promoted. Focusing on building an anti-bullying environment at school might be useful to reduce the prevalence of bullying. Appropriate interventions need to be undertaken by various stakeholders to ensure an anti-bullying program is implemented in all schools. 


\section{References}

[1] Baiden P, Kuuire VZ, Shrestha N, Tonui BC, Dako-Gyeke M, Peters KK. Bullying victimization as a predictor of suicidal ideation and suicide attempt among senior high school students in Chana: results from the 2012 Chana Global School-Based Health Survey. ] Sch Violence. 2019;18(2):300-17.

[2] Olweus D. Bullying or peer abuse at school: facts and intervention. Curr Dir Psychol Sci. 1995;4(6):196-200.

[3] Wolgast A, Donat M. Cultural mindset and bullying experiences: an eight-year trend study of adolescents' risk behaviors, internalizing problems, talking to friends, and social support. Child Youth Serv Rev. 2019;99:257-69.

[4] Cheng YL, Newman IM, Qu M, Mbulo L, Chai Y, Chen Y, et al. Being bullied and psychosocial adjustment among middle school students in China. J Sch Health. 2010;80(4):193-9.

[5] Pontes NM, Ayres CG, Lewandowski C, Pontes MC. Trends in bullying victimization by gender among US high school students. Res Nurs Health. 2018;41:243-51.

[6] van der WerfC. The effects of bullying on academic achievement. Rev Desarro y Soc. 2014;74:275-308.

[7] UNICEF. Adolescents and Youth 2019 [Online]. Available at: https://www.unicef.org/indonesia/children_2834.html [Accessed: 08-Mar2019].

[8] UNICEF. Laporan Tahunan Indonesia 2015. UNICEF Lap. Tah. Indones. 2015, pp. 1-19, 2015.

[9] Kurniasari A, Wismaayanti YF, Irmayani, Husmiati, Widodo N, Susantyo B. Survei Kekerasan Terhadap Anak Indonesia Tahun 2013. In Survei KekerasanTerhadap Anak Indonesia Tahun 2013. Jakarta: Kementerian Sosial, 2013.

[10] Kemenkes. Perilaku Berisiko Kesehatan pada Pelajar SMP dan SMA di Indonesia [Violence Against Indonesian Children Survey 2013]. Jakarta: Kemenkes, 2015, p. 1-116.

[11] KemenPPPA. Anak indonesia, apakah beban atau solusi? - stop kekerasan, bullying dan intimidasi 2016 [Indonesian children, is it a burden or a solution? - stop violence, bullying and intimidation 2016]. Jakarta: KemenPPPA. Available: https://www.kemenpppa.go.id/index.php/page/read/30/507/anak-indonesia-apakah-beban-atau-solusi-stop-kekerasan-bullying-danintimidasi. Accessed: 08-Mar-2019.

[12] Priesman ER, Wright LE. Actions speak louder than words: examining the relationship between violent behaviors and bullying victimization among adolescents. Violence Cend. 2018;5(4):259-63.

[13] Duggins SD, Kuperminc CP, Henrich CC, Smalls-Clover C, Perilla ]L. Aggression among adolescent victims of school bullying: Protective roles of family and school connectedness. Psychol Violence. 2016;6(2):205.

[14] Nansel TR, Overpeck MD, Haynie DL, Ruan W], Scheidt PC. Relationships between bullying and violence among US youth. Arch Pediatr Adolesc Med. 2003;157(4):348.

[15] Ncontsa VN, Shumba A. The nature, causes and effects of school violence in South African high schools. South African ] Educ. 2013;33(3):1-15.

[16] Mncube V, Harber C. The dynamics of violence in South African schools. Journal of Sociology and social Anthropology $2014 ; 5(1): 144$.

[17] Demanet ], Van Houtte M. The impact of bullying and victimization on students' relationships. Am ] Heal Educ. 2012;43(2):104-13.

[18] World Health Organization. Bullying and Physical Fights Among Adolescents Key Facts and Figures. Geneva: WHO, 2016.

[19] Pengpid S, Peltzer K. Bullying and its associated factors among school-aged adolescents in Thailand. Scientific World ]. 2013;2013:254083.

[20] Murshid NS. Bullying victimization and mental health outcomes of adolescents in Myanmar, Pakistan, and Sri Lanka. Child Youth Serv Rev. 2017;76:163-9.

[21] Kubwalo HW, Muula AS, Siziya S. Prevalence and correlates of being bullied among in - school adolescents in Malawi : results from the 2009 Clobal School-Based Health Survey. Malawi Med ]. 2013;25:12-14.

[22] Abdirahman HA, Bah TT, Shrestha HL, Jacobsen KH. Bullying, mental health, and parental involvement among adolescents in the caribbean. West Indian Med J. 2012;61(5):504-8.

[23] Pengpid S, Peltzer K. Prevalence, demographic and psychosocial correlates for school truancy among students aged 13-15 in the Association of Southeast Asian Nations (ASEAN) member states. J Child Adolesc Ment Health. 2017;29(3):197-203.

[24] Marela G, Wahab A, Marchira CR. Bullying verbal menyebabkan depresi remaja SMA Kota Yogyakarta [Verbal bullying causes depression in high school adolescents in Yogyakarta City]. Ber Kedokt Masy. 2017;33(1):43.

[25] World Health Organization. 2015 CSHS Indonesia Questionnaire. 2015 [Online]. Available: https://www.who.int/ncds/surveillance/gshs/2015_CSHS_Indonesia_Questionnaire.pdf.

[26] Scott ]C, Moore SE, Sly PD, Norman RE. Bullying in children and adolescents: a modifiable risk factor for mental illness. Aust New Zeal ] Psychiatry. 2014;48(3):209-12.

[27] Elgar F], McKinnon B, Walsh SD, Freeman ], D Donnelly P, de Matos MG, et al. Structural determinants of youth bullying and fighting in 79 countries. J Adolesc Health. 2015;57(6):643-50.

[28] Han Z, Zhang G, Zhang H. School bullying in urban China: prevalence and correlation with cchool climate. Int ] Environ Res Public Health. 2017;14(10):1116.

[29] Japar M. The improvement of Indonesia students 'Engagement in civic education through case-based learning'. ] Soc Stud Educ Res. 2018;9(3):27-44.

[30] Badr HE, Francis K. Psychosocial perspective and suicidal behaviors correlated with adolescent male smoking and illicit drug use. Asian ] Psychiatr. 2018;37:51-7.

[31] Ministry of Health, Report of the 2016 Sri Lanka Clobal School-based Student Health Survey Covernment of Sri Lanka, January. Colombo: Ministry of Health Srilanka, 2016.

[32] Silva MI, Pereira B, Mendonça D, Nunes B, Oliveira W. The involvement of girls and boys with bullying: an analysis of gender differences. Int ] Environ Res Public Health. 2013;10(12):6820-31. 
[33] Kim YK, Okumu M, Small E, Nikolova SP, Mengo C. The association between school bullying victimization and substance use among adolescents in Malawi: the mediating effect of loneliness. Int ] Adolesc Med Health. 2018:1-9.

[34] Siziya S, Rudatsikira E, Muula AS. Victimization from bullying among school-attending adolescents in grades 7 to 10 in Zambia. ] Inj Violence Res. 2012;4(1):30-5.

[35] Case KR, Cooper M, Creamer ML, Mantey D, Kelder S. Victims of bullying and tobacco use behaviors in adolescents: differences between bullied at school, electronically, or both. J Sch Health. 2016;86(11):832-40.

[36] Almuneef M, Saleheen HN, ElChoueiry N, Al-Eissa MA. Relationship between childhood bullying and addictive and anti-social behaviors among adults in Saudi Arabia: a cross-sectional national study. Int ] Adolesc Med Health 2017, doi: 10.1515/ijamh-2017-0052.

[37] Gaete ], Tornero B, Valenzuela D, Rojas-Barahona CA, Salmivalli C, Valenzuela E, et al. Substance use among adolescents involved in bullying: a cross-sectional multilevel study. Front Psychol. 2017;8:1056.

[38] Peltzer K, Pengpid S. Loneliness and health risk behaviors among ASEAN adolescents. Iran ] Psychiatry Behav Sci. 2017;11 (3):e7691.

[39] Paradeisioti A, Papacosta ES, Giannakopoulos G, Kolaitis G. Bullying, peer victimization, and emotional problems in Cypriot adolescents referred to mental health services - a comparison of normative and clinical data. J Sch Violence. 2019;18(1):134-45.

[40] Acquah EO, Topalli P-Z, Wilson ML, Junttila N, Niemi PM. Adolescent loneliness and social anxiety as predictors of bullying victimisation. Int ] Adolesc Youth. 2016;21(3):320-31.

[41] Kochenderfer-Ladd B, Wardrop ]L. Chronicity and instability of children's peer victimization experiences as predictors of loneliness and social satisfaction trajectories. Child Dev. 2001;72(1):134-51.

[42] Graham S, Juvonen ]. A social cognitive perspective on peer aggression and victimization. Ann Child Dev. 1998;13:23-70. 